\title{
Hypnosis and Neuro-degenerative Pathology, Towards a Reassurance of the Anxious Symptomatology
}

Parra Alain', Rossi Roxanne ${ }^{2 *}$, Vaillant Ciszewicz ${ }^{2}$ and Anne J ulie ${ }^{3}$

${ }^{1}$ Faculty of Hypnotherapist, University of Nice Sophia Antipolis, France

${ }^{2}$ Psychologist Specialized in Gerontology, University of Nice Sophia Antipolis, France

${ }^{3}$ Psychologist Specialized in Gerontology, University of Nice Sophia Antipolis, France

*Corresponding author: Rossi Roxanne, Psychologist Specialized in Gerontology, University of Nice Sophia Antipolis, France

Received: June 15, 2015; Accepted: J uly 30, 2015;

Published: August 25, 2015

\section{Introduction}

Hypnosis is a therapeutic approach, often undermined in its overall use. Indeed, some masters of hypnosis show as "the hypnotist MESSMER," now widely publicized in French-speaking countries, contribute to assert the effectiveness of this therapeutic exception, without - and this is unfortunate - respect the ethical dimension of the practice. That is why we will try to briefly define what hypnosis while enhancing its tools. We will try a second time to highlight the practice of hypnosis in gerontology and particularly in the context of neuro-degenerative diseases.

\section{Towards a definition of hypnosis}

Hypnosis as Milton s [1-4] corresponds to "a state of consciousness in which you are about you a call, with an understanding and ideas, to allow it to use that understanding and ideas within its own learning repertoire. " We assume that each of us has a healing power and that this therapy allows the patient to access without effort or suffering to an unconscious change occurring during the hypnotic work. Hypnosis then allows access to the unconscious that is as "blocked". This blockage often causes the onset of symptoms of organic diseases or behavioral disorders. Thanks to the genius of Milton ERICKSON, the symptom is not an enemy but an ally with whom the patient work. The hypno-therapist in turn is a guide that will refer the patient to its internal resources.

The traditional hypnosis, inherited the Nancy School Feller [5] or CHARCOT, ${ }^{1}$ used direct suggestion techniques to achieve an altered state of consciousness. This therapy can be defined according BIOY, WOOD and CELESTIN-Lhopiteau [6] as "a state of psychological operation by which a subject in connection with a practitioner, experimenting with a wider field of consciousness." This is indeed a modified state of consciousness, similar to what we might call the paradoxical saver that creates a feeling of relaxation while remaining fully aware of the environment in the here and now. Salem [7] evokes one of the key processes of the method: "dissociation". It could be defined as the art of dividing attention into parts.
ERICKSON evokes a state that "amplifies the perception of certain components of the experience while reducing the perception of other components." In these terms we could define the hypnotic experience as a focusing of attention processes and dissociation. Fromage [8] evokes the patient under hypnosis is in a situation where there is both "physically present and mentally absent and yet conscious of all." This particular state of attention or modified conscience is clean to each individual, it is also natural and everyday (such as when we go home after a long day of work, we drive our car without even paying attention to the road is yet so a pedestrian crossing in front of us we will be able to react, or directly after a movie). We know that the imaginary force is surprising; it also calls on the will and will influence the perception of the reality experienced by a patient. We use foci of attention, dissociation, inductions, anchoring techniques and generally metaphors in our practices.

\section{Hypnosis and Alzheimer's disease: a questioning}

But then what about the use of hypnosis with patients with neurodegenerative pathology? Can I practice hypnosis with patients with disorders of attention and memory? Is there a long-term therapeutic effect of hypnosis is if the patient forgetting to measure? This therapeutic it can reduce behavioral disorders? Salem [9] highlights the fact that hypnosis is possible work with the patient cognitively impairing since hypnosis constitute body psychotherapy. We have chosen to focus from a methodological point of view to inductions and suggestions. This is the gateway to the altered state of consciousness. This is to allow the emergence of an intuitive experience to the world and to itself according Salem [10,11]

François Roustang [12] thinks the memory disorders and temporomandibular spatial orientation should not be too much brake on the practice of hypnosis (no need to appeal to the past), but it is possible to work self-giving the revaluation regarding the possibility of activating new potentials. However, other authors do not share this view, saying that in Alzheimer's disease, mental and cognitive abilities of the subject do not achieve an altered state of consciousness.

We used relaxation techniques, therapeutic metaphors
Ann Depress Anxiety - Volume 2 Issue 5 - 2015

ISSN : 2381-8883 | www.austinpublishing group.com

Roxanne et al. () All rights are reserved 
induced in what could be seen as an ordinary conversation. The starting point diverges since the patient undergoes an alteration in cognitive, language skills, and a persecutor and scary experiences the environment. Furthermore, no therapeutic application will be made and we will be cut by the said aspect of "motivational" inherent in any therapeutic device. The therapeutic alliance will be effective so far. It is clear that the therapist must assign to certain belies its belief in the existence - or survival - of a psychic life under the debris of the degenerative disease. The hypnotic trance is it accessible to the insane? Do not is there a flaw of the imagination that is lacking? An internal focus based on it is imaginary process also accessible? The use of symbolic language to communicate with is it denies the unconscious relevant? We will attempt to answer these questions.

\section{Device Framework and the meeting}

The meeting took place in a nursing home-type institution in NICE. The patient suffers from Alzheimer's disease at a moderate stage. Despite the limited capacity of its episodic memory, Ms. Apple, 92, (entry into institution four months ago following a loss of independence) was able to tie the effective therapist transference relationship (permanent link). Drug treatment of the resident is composed of neuroleptic: Tiapridal (5 drops morning / evening if necessary), a family of anxiolytic Benzodiazepines: seresta (10mg morning and evening) and two doliprane capsules. The resident is a victim of verbal agitation accompanied by increased anxiety. The meeting takes place in the living room, panicked, she screams, cries and his speech is incomprehensible. The clinician proceeds primarily to an assessment of Algoplus type of pain that indicates a score of $2 / 4$. We can therefore hypothesize a somatic pain correlated with marked anxiety and a depressive syndrome in connection with the loss of spatial and temporal references and the bedridden patient The speech of Mrs. Apple is moving towards the physical and mental complaints. The clinician means his presence by his countenance, his benevolence, naming and occurring in turn. The clinician proposes to accompany Mrs. Apple in a quieter place: his room. Finally, she says: "Yes agree ... (Silence). I know where I am! I'm completely besotted, "then she sobs bitterly. The demand here is not in a reply to his question, but more in acquiescence or in understanding the condition in which it is located. She lies on her bed spontaneously the session can begin. The clinician tries to establish a warm climate, empathic and reassuring emphasizing his presence and tell him that we are both in his room at the nursing home.

The tears subside gradually. The hypnotic relationship begins by focusing attention on the voice of the therapist (soft and quiet) and its indications. This is to handle communication in the own frame of reference to the patient. The therapist should be particularly attentive to the signs conscious and unconscious emerging during the session.

Ms Apple shows no understanding of aphasia, which allows us to use verbal and non-verbal. It is free to act as she wishes.

The therapist asks the patient to focus attention on an object, but prefers to ignore. It is here that we could say that the mode of induction is not unique but depends on the patient's singularity; the clinician must therefore be available and express their creative skills and adaptability to the therapeutic setting. A breathing exercise is then set up between therapist and Mrs. Apple to calm his breathing and focus our attention on body movements' products. Here is how the clinician implements induction, although the therapeutic work begins when the therapist begins to exchange with his patient. The clinician lives fully the experience with the patient, while maintaining its ability to decentralize the experience at times to observe the language or bodily reactions. We can consider than any focus leads to a trance state, such as in situations of everyday life, this is what Simon [13] calls spontaneous hypnotic states (eg after a movie some seconds are necessary to regain a foothold with reality). The year begins; "Okay Mrs. Apple, hear the sound of my voice, feel the warmth of my hand in yours, listen to the quiet, let you guide through me, in a few moments you will feel perfectly relaxed and get into a different state calm and listen to your body. "

The patient is now in a state of active receptivity, allowing him to let go of conscious mechanisms underpinned by the "I". Breathing game set up by the clinician and the patient generates a decrease in anxiety resulted in the body that relaxes (hypnotic trance). The therapist then guides the patient by the sound of his voice and gets closer to its reality in an attempt to build another one. The clinician apply on body sensation by performing a real scan of each part of the body of Mrs. Apple, starting with the feet to the head to achieve maximum state of relaxation induction and suggestions. The resident still breathing calmly and clinical observation attests small involuntary movements at the mention of the various parts of his body.

Metaphors are also used during this session always adapting their content to the particularity of Mrs. Apple order not to dislocate his attention but rather to keep it "Now you feel relaxed and soothed. Your whole body relaxes; let yourself be overwhelmed by this pleasant sensation. Your feet are light, feel like they are relaxed, your legs become lighter, your bust also relax your arms slowly, everything calmly. Your face relaxes slowly... Enjoy this quiet moment, your whole body is light, like a feather in the wind, and he could almost fly".

The clinician continues with the evocation of a story. This is a trip in a forest (the patient previously appreciated the nature walks) where one sees only the green trees, where you hear only the chirping of birds, the creaking of the wood, where we breathe vegetation odors. (This metaphorical tale emerges from the imagination of the therapist, he leads a work focus and imagination, is also a coconstruction since it is based on information gathered with the family during the institutionalization of the patient). Mrs. Apple must now focus its attention on images of smells and sensations (place of). The clinician then accompanied his patient through a trail. At the end of this trail is a beautiful hot air balloon in which he invites him to mount. It rises gently over the trees to collect the tiny world around. The clinician asks Mrs. Apple to focus on anxiety and imagine that it remains far from the nettles and other weeds of the forest. We end the trip on a cloud, calm and serene, safe and gentle. We find that Mrs. Apple completely let go at this point, his hands are open she let go the hand of the clinician it held firmly. His whole body is relaxed: she fell asleep. The clinician if he questions her against transfer is somewhat destabilized by this unexpected but continues with the introduction of a hypnotic suggestion: "Now you fell asleep, all relaxed and in deep relaxation, I will leave the part to be present. I will slowly move away and let you take advantage of this moment of calm and security. «The observed behavior problems disappeared during this first session. When Mrs. Apple wakes up, it's dinner time, it is quiet and peaceful. 


\section{The therapeutic effects}

We see through this clinical vignette reduced anxiety: the resident falls asleep. The hypnosis work he represents a focusing too costly attention? Is she reached a mental exhaustion and / or somatic? Is it possible that hypnosis allows him to relocate his conscious state (reality) of psychological distress linked to the disease? We cannot deny that the induced state provokes in her a true relaxation. The symbolic language used through the metaphors used to contact this circularity communication (considering alongside the silence). During another meeting with Mrs. Apple, it does not fall asleep. It presents well-being indicators and hypnotic trance (face relaxed and muscle relaxation). The resident is immersed in a pseudo-lethargic trance state (tendency to passivity, not resistors in place). Victor SIMON [13] points out that "The metaphor conveys a symbolic message through analogy." The unconscious mind will be able to dissect and understand this language, which does not produce significant frontal attacks. However we must remain flexible and careful in practice of hypnosis in the elderly. The key word of the practice of hypnosis in elderly demented remains: adaptation and flexibility.

Now consider a patient with Alzheimer's disease at a severe stage, hypnosis remains possible since the latter, even without access to verbal language may be through the body, and most particularly affected (repetitive movement on the body the elderly, circles drawn on the hands). The therapist will however, be receptive and containing get creative to try to focus the patient's attention denies. The device created by the non-drug approach to the environment (soft music, essential oil diffusion, light therapy) allows the resident to allay anxiety and thus a focus of attention becomes possible and a dissociation the disruptive element in the origin of anxiety and depressive problems of time (these problems are cyclical). We mention briefly another patient (nursing homes), Mrs. Sun, 84 years, a victim of Alzheimer's disease in moderate to severe stage. We have worked with that person on the type of efficient induction. It is the sensory spiral is seen as too intrusive and again we note that the work on body size allows focus. Creating a safe place also allowed the patient to feel soothed in one sitting, before returning home.

In conclusion, the clinician will need to be creative and appropriate protocols in his clinic and not learn and repeat the robotic way that would alienate the subjective dimension of being and probably would end the alliance therapeutic create with hypnosis.

\section{References}

1. Erikson M, Rossi EL. The complete Articles of Milton H. Erickson. Volume 1: The nature of hypnosis and suggestion, New York, Irvington? 1980.

2. Erikson M, Rossi EL. The complete Articles of Milton H. Erickson. Volume 2: Alteration by hypnosis sensory, perceptual and psychophysiological, New York, Irvington? 1980

3. Erikson M, Rossi EL. The complete Articles of Milton H. Erickson. Volume 3 Study by hypnosis psychodynamic processes, New York, Irvington? 1980.

4. Erikson M, Rossi EL. The complete Articles of Milton H. Erickson. Volume 4 Innovations in hypnotherapy, New York, Irvington? 1980.

5. Feller GJ. Liebeault apostle of hypnosis. Metz, Serpenoise editor. 2003.

6. Bioy A, Wood C, Celestin-Lhopiteaul, MICHAUX D. Hypnosis to Help memory. Paris: Dunod. 2010.

7. Salem G. Hypnotic techniques. In Salem, \& Bonvin, Cure by hypnosis Elsevier-Masson, Paris. 2012.

8. Cheese Group B. Relaxation with institutional elderly. Psy field. 2001; 24 131-144.

9. Salem G. Hypnotic trance. In Salem, \& Bonvin, Cure by hypnosis, ElsevierMasson, Paris. 2012

10. Salem G. Hypnotherapy. In Salem, \& Bonvin, Cure by hypnosis, 5th edition Elsevier-Masson. 2012; 56-79.

11. Salem G. Small toolbox hypnotherapists. In Salem, \& Bonvin, Cure by hypnosis, 5th edition. Elsevier-Masson. 2012; 95-155

12. Roustang F. What hypnosis The Editons Midnight. 2003.

13. Victor S. Good use of hypnosis, Robert Lafont, Paris. 2000.
Ann Depress Anxiety - Volume 2 Issue 5 - 2015

ISSN : 2381-8883 | www.austinpublishinggroup.com

Roxanne et al. (C) All rights are reserved
Citation: Alain P, Roxanne R, Ciszewicz V and Julie A. Hypnosis and Neuro-degenerative Pathology, Towards a Reassurance of the Anxious Symptomatology. Ann Depress Anxiety. 2015; 2(5): 1060. 